
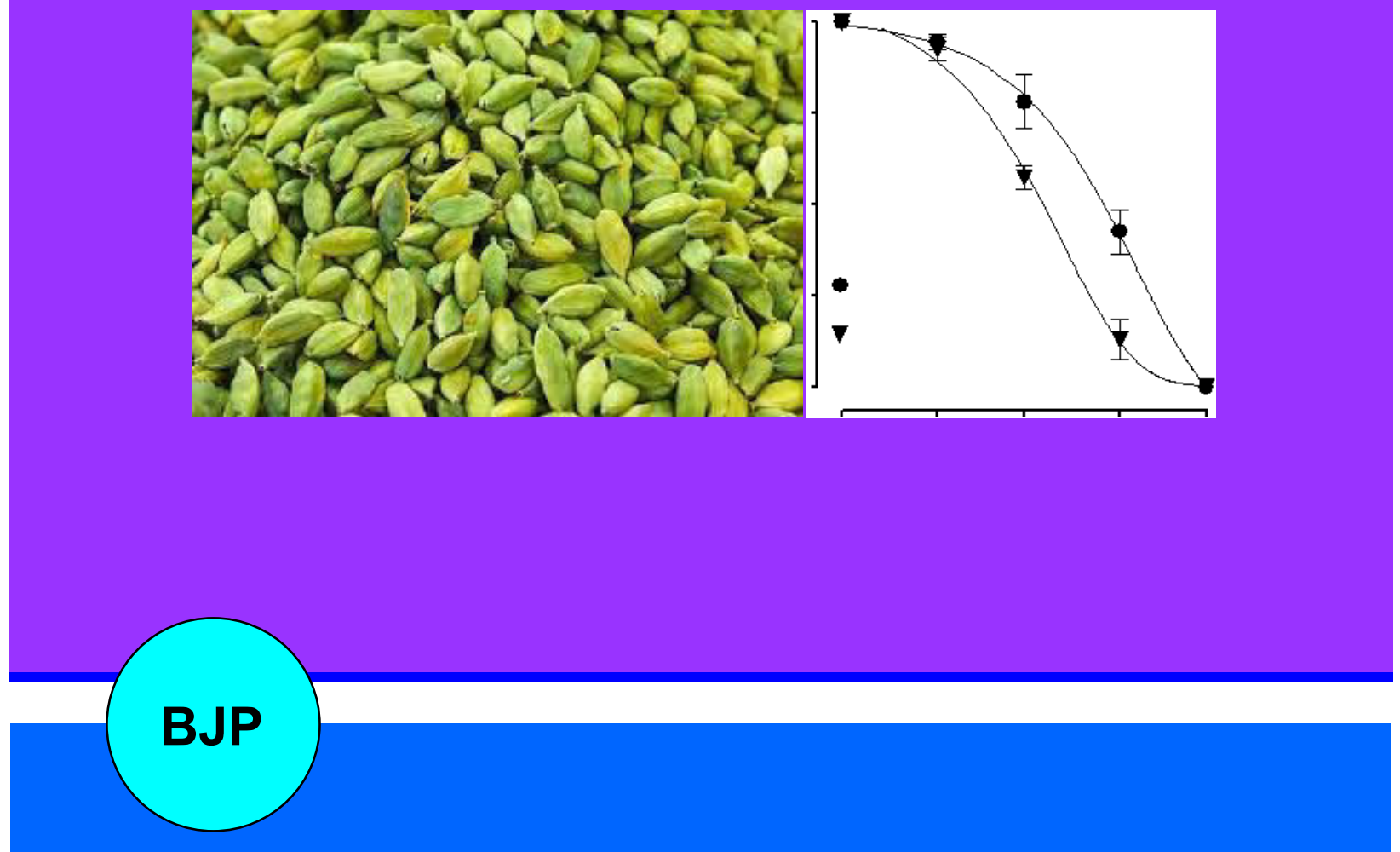

Bangladesh Journal of Pharmacology

Research Article

Pharmacological basis for the medicinal use of cardamom in asthma 


\title{
Pharmacological basis for the medicinal use of cardamom in asthma
}

\author{
Arif-ullah Khan',2, Qaiser Jabeen Khan',3 and Anwarul-Hassan Gilani' \\ ${ }^{1}$ Natural Product Research Division, Department of Biological and Biomedical Sciences, Aga Khan University \\ Medical College, Karachi 74800, Pakistan; ${ }^{2}$ Institute of Pharmaceutical Sciences, Kohat University of Science and \\ Technology, Kohat 26000, Pakistan; ${ }^{3}$ Faculty of Pharmacy and Alternative Medicine, The Islamia University of \\ Bahawalpur 63100, Pakistan.
}

\begin{tabular}{|c|c|}
\hline \multicolumn{2}{|l|}{ Article Info } \\
\hline Received: & 30 July 2011 \\
\hline Accepted: & 1 August 2011 \\
\hline Available Online: & 3 August 2011 \\
\hline \multicolumn{2}{|c|}{ DOI: 10.3329/bjp.v6i1.8133 } \\
\hline \multicolumn{2}{|c|}{$\begin{array}{l}\text { Cite this article: } \\
\text { Khan A, Khan QJ, Gilani AH. Phar- } \\
\text { macological basis for the medicinal } \\
\text { use of cardamom in asthma. Bangla- } \\
\text { desh J Pharmacol. 2011; } 6: 34-37 \text {. }\end{array}$} \\
\hline
\end{tabular}

\section{Abstract}

Cardamom (Elettaria cardamomum) is widely used in folk medicine for the treatment of asthma. This study describes its airways relaxant potential, with elucidation of possible underlying mechanism. Crude extract of cardamom which tested positive for alkaloids, flavonoids, saponins, sterols and tannins, when tested against carbachol-mediated bronchoconstriction in rats under anesthesia, dose-dependently $(10-100 \mathrm{mg} / \mathrm{kg})$ suppressed the carbachol (1 $\mu \mathrm{mol} / \mathrm{kg}$ )-evoked increase in the inspiratory pressure. In isolated rabbit trachea tissues, crude extract of cardamom caused relaxation of both carbachol $(1 \mu \mathrm{M})$ and high $\mathrm{K}^{+}(80 \mathrm{mM})$-induced contractions, like that caused by verapamil, suggesting its $\mathrm{Ca}^{++}$channel blockade action. These results indicate that cardamom exhibits bronchodilatory effect, mediated through $\mathrm{Ca}^{++}$antagonist mechanism, which provides sound mechanistic background for its medicinal use in asthma.

\section{Introduction}

Elettaria cardamomum Maton (family: Scitaminaceae) commonly known as "cardamom" and locally known as "elaichi" is a perennial herb, indigenous to India, Pakistan, Myanmar and Sri Lanka (Nadkarni, 1976). In addition to its wide use for culinary purpose, cardamom has been used in traditional medicine for asthma, constipation, colic, diarrhea, dyspepsia, hypertension, epilepsy and is considered useful as antibacterial, antifungal, antiviral, carminative, diuretic and stomachic (Kapoor, 1990; Duke et al., 2002). Phytochemical studies revealed that cardamom contains a-terpineol, myrcene, heptane, subinene, limonene, cineol, menthone, a-pinene, $\beta$-pinene, linalol, nerolidol, $\beta$-sitostenone, phytol, eugenyl acetate, bisabolene, borneol, citronellol, geraniol, geranyl acetate, stigmasterol and terpinene (Gopalakrishnan et al., 1990; Duke, 1992). Despite the fact that cardamom has been used medi- cinally, it has not been widely studied to rationalize its use in hyperactive status of airways, asthma. In this study, we evaluated that the bronchodilatory effect of cardamom is mediated through $\mathrm{Ca}^{++}$channel blockade, which provide pharmacological rational for its effectiveness in the asthma.

\section{Materials and Methods \\ Plant material and preparation of extract}

Dried fruits of cardamom were purchased from a local market in Karachi and the sample voucher (EC-SE-0704-54) was submitted to the Department of Biological and Biomedical Sciences herbarium, Aga Khan University, Karachi. After cleaning of adulterant material, the fruits were ground with an electric grinder into a coarse powder. Extraction and fractionation was carried out as 
described previously. About $986 \mathrm{~g}$ of ground material was soaked in 4 liters of the aqueous-methanol (70\%) for three days with occasional shaking. It was filtered through a muslin cloth and then through a Whatman qualitative grade 1 filter paper. This procedure was repeated twice and the combined filtrates were evaporated on rotary evaporator under reduced pressure ($760 \mathrm{mmHg}$ ) to a thick, semi-solid pasty mass of dark brown color; i.e. the crude extract of cardamom, yielding approximately $10.8 \%$, soluble in saline/distilled water.

\section{Animals}

Animals used in this study, such as Sprague-Dawley rats (230-260 g) and rabbits (1.5-2.0 kg) of either sex and local breed were housed at the Animal House of the Aga Khan University, maintained at $23-25^{\circ} \mathrm{C}$. Experiments performed complied with the rulings of the Institute of Laboratory Animal Resources, Commission on Life Sciences, National Research Council (1996) and approved by Ethical Committee of Aga Khan University.

\section{Chemicals}

Carbachol, salbutamol and pentothal sodium (thiopental sodium) were respectively obtained from Sigma Chemicals Co., USA, Glaxo Wellcome and Abbot Laboratories, Karachi, Pakistan. Chemicals for Krebs solutions include: Potassium chloride (Sigma Chemical Company), calcium chloride, glucose, magnesium sulfate, potassium dihydrogen phosphate, sodium bicarbonate and sodium chloride (E. Merck, Germany). The chemicals used in phytochemical analysis include: Acetic anhydride, aluminum chloride, ammonium hydroxide, Dragendorff's reagent, ferric chloride (Sigma Chemical Co, USA), benzene, chloroform, hydrochloric acid and petroleum ether (BDH Laboratory supplies, England). All the chemicals used were of analytical grade available.

\section{Phytochemical screening}

Preliminary screening of the plant extract for various phytochemical classes was carried out following the reported methods (Gilani et al., 2007). Alkaloids were tested by using Dragendorff's reagent. Appearance of yellow color with $\mathrm{AlCl}_{3}$ reagent and green or black with aqueous $\mathrm{FeCl}_{3}$ detects flavonoids and tannins respectively. Plant material treated with petroleum ether and subsequently extracted with $\mathrm{CHCl}_{3}$ was noted for green to pink or pink to purple color after reaction with acetic anhydride and $\mathrm{HCl}$ in succession to detect sterols and terpenes respectively. Saponins were detected on the basis of froth upon vigorous shaking. The observation of yellow florescence under UV light on filter paper impregnated with the vapors from boiling extract indicates the presence of coumarins. Benzene extract prepared from acidified plant material was treated with
$\mathrm{NH}_{4} \mathrm{OH}$ for anthraquinones based on the appearance of pink, violet or red color.

\section{Bronchodilatory activity}

Rats were anaesthetized with sodium thiopental (Pentothal, $80-100 \mathrm{mg} / \mathrm{kg}$, i.p.), than incubated with a tracheal tube and ventilated with a volume ventilator (Miniature ideal pump, Bioscience, UK) adjusted at a rate of 70-80 strokes/min to deliver $7-10 \mathrm{~mL} / \mathrm{kg}$ of room air. A polyethylene catheter was inserted into the jugular vein for drugs administration. Changes in airways resistance (mmHg) were measured by a pressure transducer (MLT -1199) connected to side arm of tracheal cannula and recorded by PowerLab 4/25 with running chart software via Quad bridge amplifier (ADInstruments, Australia). Bronchoconstriction was induced with carbachol $(1 \mu \mathrm{mol} / \mathrm{kg})$, which was reversed within 7-10 min. The test drug was given to the animals 5-8 min prior to administration of carbachol. The responses were expressed as the percent reduction of the carbachol-evoked bronchospasm (Khan and Gilani, 2009).

\section{Isolated rabbit trachea}

Trachea from rabbit, sacrificed by blow on back of head was dissected out and kept in Kreb's solution. The tracheal tube was cut into rings, 2-3 $\mathrm{mm}$ wide, each containing about two cartilages. Each ring was opened by a longitudinal cut on ventral side, forming a tracheal chain with smooth muscle in the center and cartilaginous portions on the edges. Each preparation was then mounted in $20 \mathrm{~mL}$ tissue bath containing Kreb's solution, maintained at $37^{\circ} \mathrm{C}$ and aerated with carbogen $\left(5 \% \mathrm{CO}_{2}\right.$ in $\left.95 \% \mathrm{O}_{2}\right)$. The composition of $\mathrm{Kreb}^{\prime}$ s solution was (mM): $\mathrm{NaCl} 118.2, \mathrm{NaHCO}_{3} 25.0, \mathrm{CaCl}_{2} 2.5, \mathrm{KCl} 4.7$, $\mathrm{KH}_{2} \mathrm{PO}_{4} 1.3, \mathrm{MgSO}_{4} 1.2$ and glucose 11.7 (pH 7.4). A tension of $1 \mathrm{~g}$ was applied to each of the tracheal strip and was kept constant throughout the experiment. The tissue was equilibrated for 1 hour before the addition of any drug. Then sustained contractions of the agonists, carbachol $(1 \mu \mathrm{M})$ and/or $\mathrm{K}^{+}(80 \mathrm{mM})$ were obtained and tracheo-relaxant effect of the test material was assessed by adding in a cumulative fashion. Carbachol is a cholinergic agonist, known to cause bronchoconstriction via stimulation of muscarinic receptors (Gilani et al., 2010). High $\mathrm{K}^{+}(>30 \mathrm{mM})$ is known to cause smooth muscle contractions through opening of voltagedependent L-type $\mathrm{Ca}^{++}$channels, thus allowing influx of extracellular $\mathrm{Ca}^{++}$causing a contractile effect and the substance causing inhibition of high $\mathrm{K}^{+}$-induced contraction is considered as inhibitor of $\mathrm{Ca}^{++}$influx (Godfraind et al., 1986). The changes in isometric tensions of the tracheal strips were measured via a force -displacement transducer (FT-03) using a Grass model 7 Polygraph (Grass Instrument Company, Quincy, MA, USA). 


\section{Statistical analysis}

The data expressed are mean \pm standard error of mean (SEM, $\mathrm{n}=$ number of experiment) and the median effective concentrations $\left(\mathrm{EC}_{50}\right)$ with $95 \%$ confidence intervals $(\mathrm{CI})$, analyzed by using GraphPad program (GraphPAD, San Diego, CA, USA).

\section{Results}

Crude extract of cardamom was found to contain alkaloids, flavonoids, saponins, sterols and tannins while tested negative for the rest of classes (data not shown).

Crude extract of cardamom at the doses of 10, 30 and $100 \mathrm{mg} / \mathrm{kg}$ caused $9.0 \pm 2.1,37.7 \pm 5.4$ and $83.4 \pm 4.4 \%$ $(\mathrm{n}=4)$ respective inhibition of carbachol $(1 \mu \mathrm{mol} / \mathrm{kg})$ evoked increase in inspiratory pressure of anaesthetized rats. Salbutamol suppressed the carbachol (1 $\mu \mathrm{mol} / \mathrm{kg})$-induced bronchoconstriction at $0.3 \mathrm{mg} / \mathrm{kg}$ by $78.7 \pm 3.9 \%(\mathrm{n}=4$; Figure 1$)$.

In tracheal preparations, pre-contracted with carbachol $(1 \mu \mathrm{M})$ and $\mathrm{K}^{+}(80 \mathrm{mM})$, crude extract of cardamom caused concentration-dependent relaxant effect, being more potent against $\mathrm{K}^{+}$, with respective $\mathrm{EC}_{50}$ values of $0.85(0.6-1.3,95 \% \mathrm{CI}, \mathrm{n}=5)$ and $0.37 \mathrm{mg} / \mathrm{mL}(0.3-0.4, \mathrm{n}=$ 4; Figure 2A). Verapamil also caused inhibitory effect, possessing higher potency against $\mathrm{K}^{+}$, with $\mathrm{EC}_{50}$ values of $0.26(0.2-0.3, n=3)$ and $0.1 \mu \mathrm{M}(0.06-0.14, \mathrm{n}=3)$ respectively (Figure $2 \mathrm{~B}$ ).

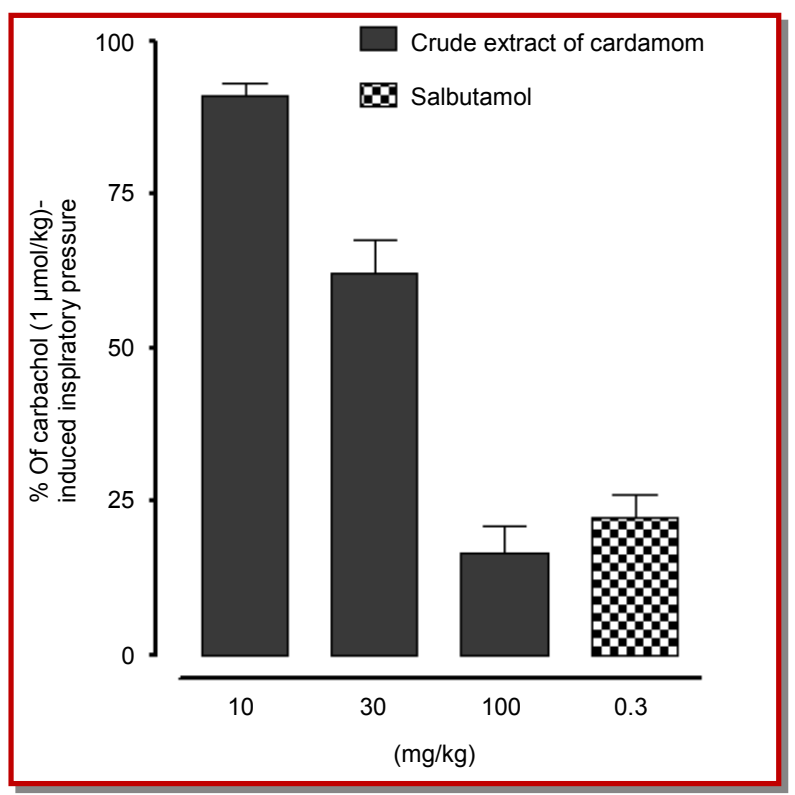

Figure 1: Bar-chart showing inhibitory effect of the crude extract of cardamom and salbutamol on the carbachol-mediated bronchoconstriction in anesthetized rats. Values shown are mean \pm SEM, $n=4$

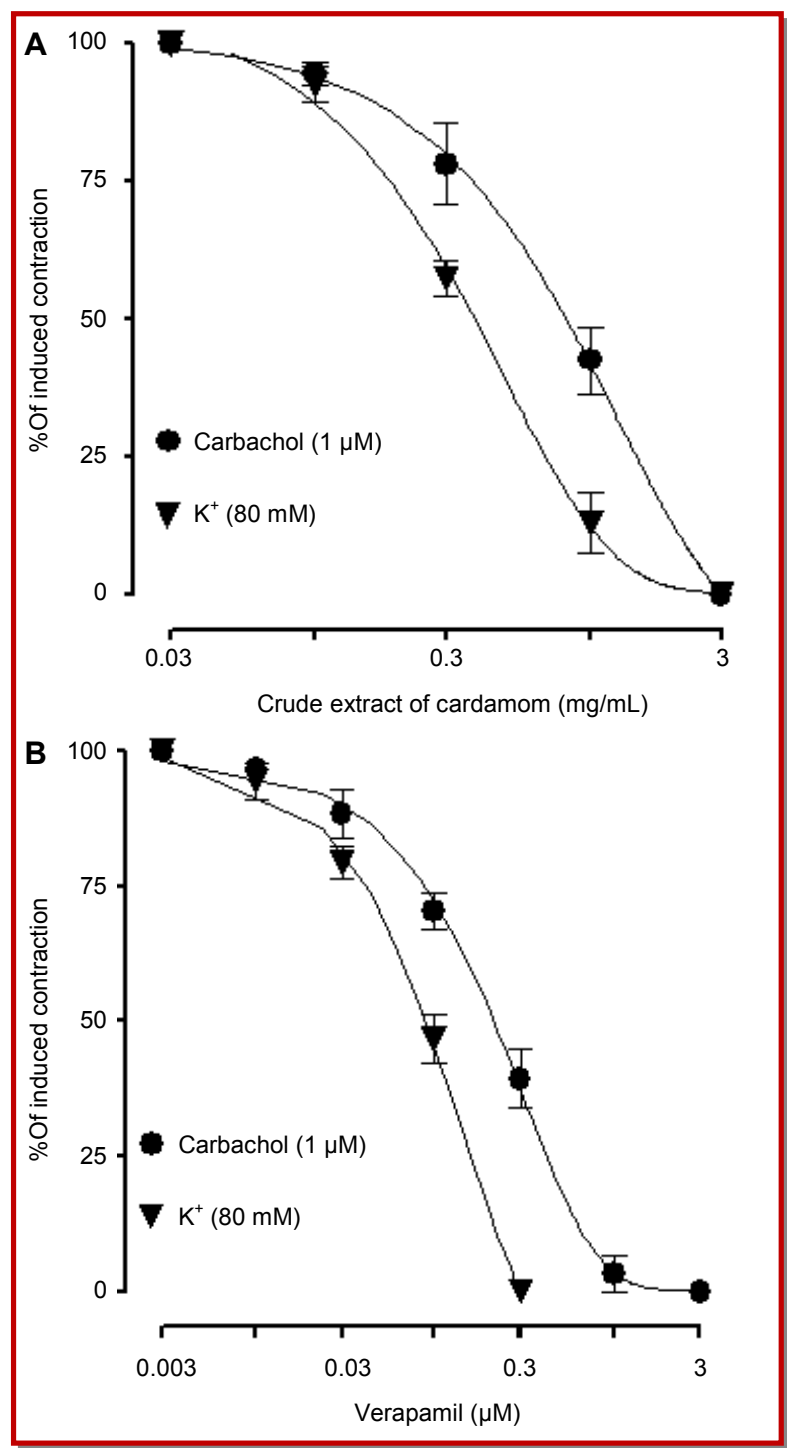

Figure 2: Concentration-dependent inhibitory effect of (A) crude extract of cardamom and (B) verapamil against carbachol and high $\mathrm{K}^{+}$-induced contractions in isolated rabbit tracheal preparations. Values shown are mean \pm SEM, $n=3-5$

\section{Discussion}

In view of the well known medicinal use in asthma, the cardamom was tested for its possible bronchodilatory effect in anaesthetized rats, where it inhibited the carbachol-evoked bronchospasm, like that caused by salbutamol, a standard bronchodilator (Barnes, 2006). The cardamom extract was then studied in isolated tracheal tissues, to elucidate the possible mode of bronchodilator action, where crude extract of cardamom caused relaxation of both carbachol and $\mathrm{K}^{+}$induced contractions, like verapamil, a $\mathrm{Ca}^{++}$antagonist (Fleckenstein, 1977) used as positive control. High $\mathrm{K}^{+}$ and carbachol are known to cause smooth muscle 
contractions through opening of L-type $\mathrm{Ca}^{++}$channel and stimulation of muscarinic receptors respectively, eventually leading to an increase in the intracellular $\mathrm{Ca}^{++}$level, resulting in airways constriction (Gilani et al., 2007). The inhibitory effect of crude extract of cardamom against the two spasmogens, indicates nonspecific tracheao-relaxant effect, mediated through $\mathrm{Ca}^{++}$ channel blocker-like mechanism (Gilani et al., 2010). $\mathrm{Ca}^{++}$antagonists are known to be effective in asthma (Ann Twiss et al., 2002) and the presence of such activity, as observed in this study may explain the medicinal use of cardamom in such disorder of airways hyperactivity.

The results of phytochemical analysis showed that cardamom contains alkaloids, flavonoids, saponins, sterols and tannins. The flavonoids are well known for their bronchodilatory activity (Ghayur et al., 2007) and the presence of such class of compounds in cardamom is likely to contribute in its airways relaxing action. However, the contribution of other constituents cannot be ignored.

\section{Conclusion}

Cardamom exhibits bronchodilatory effect, mediated through $\mathrm{Ca}^{++}$antagonist mechanism, which provides pharmacological basis for its application in the disorder of hyperactive status of respiratory system, known as asthma.

\section{Acknowledgement}

This study was supported by funds made available by Pakistan Science Foundation.

\section{References}

Ann Twiss M, Harman E, Chesrown S, Hendeles L. Efficacy of calcium channel blockers as maintenance therapy for asthma. Br J Clin Pharmacol. 2002; 53: 243-49.

Barnes PJ. Drugs for asthma. Br J Pharmacol. 2006; 147: S297S303.

Duke JA. Handbook of phytochemical constituents of GRAS herbs and other economical plants. London, CRC Press, 1992, pp 239-40.

Duke JA, Bogenschutz-Godwin MJ, DuCelliar J, Duke PK. Handbook of medicinal herbs. 2nd ed. Boca Raton, CRC Press, 2002, pp 153-54.

Fleckenstein A. Specific pharmacology of calcium in myocardium, cardiac pacemakers and vascular smooth muscle. Annu Rev Pharmacol Toxicol. 1977; 17: 149-66.

Ghayur MN, Khan H, Gilani AH. Antispasmodic, bronchodilator and vasodilator activites of $(+)$-catechin, a naturally occurring flavonoid. Arch Pharm Res. 2007; 30: 970-75.

Gilani AH, Bashir S, Khan AU. Pharmacological basis for the use of Borago officinalis in gastrointestinal, respiratory and cardiovascular disorders. J Ethnopharmacol. 2007; 114: 39399.

Gilani SN, Khan AU, Gilani AH. Pharmacological basis for the medicinal use of Zanthoxylum armatum in gut, airways and cardiovascular disorders. Phytother Res. 2010; 24: 553-58.

Godfraind T, Miller R, Wibo M. Calcium antagonism and calcium entry blockade. Pharmacol Rev. 1986; 38: 321-416.

Gopalakrishnan M, Narayanan CS, Grenz M. Non saponifiable lipid constituents of cardamom. J Agric Food Chem. 1990; 38: 2133-36.

Kapoor LD. Handbook of Ayurvedic medicinal plants. CRC Press, Boca Raton, 1990, p 172.

Khan A, Gilani AH. Antidiarrheal, antisecretory and bronchodilatory activities of Hypericum perforatum. Pharm Biol. 2009; 47: 962-67.

Nadkarni KM. Indian materia medica. $3^{\text {rd }}$ ed. Bombay, Popular Prakashan, 1976, pp 475-76.

National Research Council. Guide for the care and use of laboratory animals. Washington, National Academy Press, 1996, pp 1-7. 